Research paper

\title{
How often do we perform painful and stressful procedures in the paediatric intensive care unit? A prospective observational study
}

\author{
Manuel A. Baarslag, MD ${ }^{\text {a, * }}$ \\ Sharan Jhingoer, BSc ${ }^{a}$ \\ Erwin Ista, RN, $\mathrm{PhD}^{\mathrm{a}}$ \\ Karel Allegaert, MD, PhD ${ }^{\mathrm{a}, \mathrm{b}}$ \\ Dick Tibboel, $\mathrm{MD}, \mathrm{PhD}^{\mathrm{a}}$ \\ Monique van Dijk, MSc, $\mathrm{PhD}^{\mathrm{a}, \mathrm{c}}$ \\ a Intensive Care and Department of Pediatric Surgery, Erasmus University Medical Center - Sophia Children's Hospital, Rotterdam, The Netherlands
b Department of Development and Regeneration, University of Leuven, Leuven, Belgium
c Division of Neonatology, Department of Pediatrics, Erasmus University Medical Center - Sophia Children's Hospital, Rotterdam, The Netherlands
}

\section{A R T I C L E I N F O R M A T I O N}

\section{Article history:}

Received 9 December 2017

Received in revised form

3 April 2018

Accepted 14 April 2018

\section{Keywords:}

Paediatric intensive care

Pain

Children

Analgesia

Stress

\begin{abstract}
A B S T R A C T
Background: Adequate analgesia and sedation is crucial in critical care. There is little knowledge on the extent of painful and stressful procedures on children admitted to a paediatric intensive care unit (PICU) and its analgesic and/or sedative management.

Objective: The primary objective was to determine the number of painful and stressful procedures per patient per day in our PICU patients, including the numbers of attempts. A secondary objective was to map PICU nurses' perceptions of the painfulness of the included procedures.

Methods: A prospective, single-centre observational cohort study in a tertiary PICU. All patients admitted to the PICU over a 3-month period were eligible. Readmissions, polysomnography patients, and patients without any data have been excluded. The number of painful and stressful procedures was collected daily, and use of analgesics and sedatives was assessed and recorded daily. Twenty-five randomly assigned nurses rated the painfulness of procedures based on their personal experience using a numeric rating scale from 0 to 10 .

Results: In a 3-month period, a total of 229 patients were included, accounting for 855 patient days. The median number of painful and stressful procedures per patient per day was 11 (interquartile range $=5-23$ ). Endotracheal suctioning was the most frequent procedure (45\%), followed by oral and nasal suctioning. Arterial and lumbar puncture, peripheral IV cannula insertion, and venipuncture were scored as most painful ranging from 3 to 10 . Procedural analgesia or sedation was often not used during these most painful procedures.

Conclusions: Mechanically ventilated patients undergo more than twice as many painful procedures than non-ventilated patients, as endotracheal suctioning accounts for almost half of all. Nurses regarded skinbreaking procedures most painful; however, these were rarely treated by procedural analgosedation and only covered in the minority of cases by adequate background analgosedation.
\end{abstract}

( 2018 Australian College of Critical Care Nurses Ltd. Published by Elsevier Ltd. All rights reserved.

\footnotetext{
* Corresponding author at: Erasmus University Medical Center - Sophia Children's Hospital, Department of Intensive Care and Pediatric Surgery, P.O. Box 2060, 3000 CB Rotterdam, The Netherlands.
}

E-mail address: m.baarslag@erasmusmc.nl (M.A. Baarslag).

\section{Introduction}

Adequate sedation and analgesia (or analgosedation) are crucial elements of paediatric critical care. Paediatric guidelines recommend continuous administration of both a sedative (mainly benzodiazepines) and an analgesic (mainly opioids) ${ }^{1,2}$ to reduce pain and stress. This continuous background analgosedation may not be 
sufficient to alleviate procedural pain and distress in critically ill children, who are subjected to multiple possibly painful and stressful procedures everyday. ${ }^{3}$

Several studies have determined numbers of daily painful and stressful procedures and analgesic management in the neonatal intensive care unit (NICU), ${ }^{4-8}$ summarised in a systematic review of 18 studies which reported a mean of 7.5-17.3 daily painful procedures per patient in the NICU setting. ${ }^{9}$ Only two studies to date have addressed this issue in paediatric intensive care unit (PICU) patients. One is a retrospective multi-centre chart study published in 2011 which reported a median number of 12 (interquartile range $[I Q R]=6-18$ ) painful procedures per patient day in 799 PICU patients aged between 0 and 18 years. ${ }^{3}$ The second study, dating back to 1993 , is a single-centre, prospective observational study in 55 PICU patients aged between 0 and 12 years which reported median numbers of 2 and 3.5 procedures per day, depending on length of stay. ${ }^{10}$ These two studies were limited to painful procedures only and did not account for the numbers of procedural attempts. To provide an in-depth analysis of the prevalence of painful and stressful procedures in our PICU, a prospective observational cohort study, also including stressful procedures and numbers of attempts per procedure, was undertaken.

The aim of this study was to determine the numbers of daily painful and stressful procedures, including numbers of attempts and to determine whether there is a relationship with age, mechanical ventilation, and surgery as these factors were found to be risk factors in NICU patients. ${ }^{5-7}$ The secondary aim was to map PICU nurses' perception of the painfulness of the procedures and to evaluate procedural pharmacological analgesic and/or sedative treatment for the most frequent painful procedures.

\section{Materials and methods}

\subsection{Design, patients, and setting}

In this prospective observational cohort study, all patients admitted to the PICU between 9th May 2016 and 9th August 2016 were eligible. This PICU is a 28-bed tertiary care unit for all medical and surgical specialities-including extracorporeal life support - for children aged 0-18 years including neonates with major congenital anomalies. The centre has a standard analgosedation protocol in place that has been published previously. ${ }^{11,12}$ If a patient was admitted more than once in the study period, only the first admission was included for analysis. Patients admitted for observation only during polysomnography were excluded. The Institutional Review Board waived the need for informed consent (MEC 2016-310).

\subsection{Data collection}

A paper checklist was designed including 40 possibly painful and stressful procedures, with a blank field to add a procedure if applicable. The list was based on literature findings and expert opinion of the study team (MvD, EI, MB, KA). The checklist was tested for completeness during a 1-week pilot study among all attending PICU nurses. The data from this pilot have not been included for analysis. After this pilot study, two items were added: "Activities of Daily Living" and "Nebulising". The final version (see Appendix 1) contained 42 procedures, of which 31 were regarded painful and 11 stressful. Painful procedures were defined as skinbreaking procedures, skin-manipulating procedures or procedures involving the insertion or removal of lines, tubes, or catheters. Stressful procedures were defined as all other procedures without risk for pain, e.g. electrocardiography, magnetic resonance imaging, or computed tomography scans, physiotherapy, etc. Although painful procedures are likely to be stressful as well, we classified them separately as pain and stress and treated them differently.

The bedside nurses were instructed to record the listed procedures that each patient underwent during the shift. New checklists were provided daily to nurses on the morning shift. Furthermore, the nurses were asked to record the numbers of attempts needed to successfully perform the following procedures: heel and finger stick, venipuncture, peripheral intravenous (IV) cannula insertion, lumbar puncture, arterial puncture (arterial catheter insertion), central venous catheter insertion, nasogastric tube insertion, urinary catheter insertion, nasopharyngeal tube insertion, and endotracheal intubation. Each failed attempt and the final successful one was counted as a separate procedure in the overall analysis. Data were collected related to relevant patient characteristics such as age, gender, mechanical ventilation (collected per patient-day), extracorporeal membrane oxygenation treatment (collected per patient-day), severity of illness, and reason for admission. Severity of illness was calculated using the paediatric index of mortality-2 (PIM-2) ${ }^{13}$ score and the paediatric risk of mortality (PRISM-III) score. ${ }^{14}$ Further, any use of background analgesics, including paracetamol, non-steroidal anti-inflammatory drugs, fentanyl, morphine, tramadol, and remifentanil, and sedatives, including propofol, midazolam, lorazepam, clonidine, ketamine, chloral hydrate, and pentobarbital was assessed daily and recorded as having been received (yes/no). Procedural analgesics and sedatives were not collected prospectively. Retrospective collection of procedural drug prescription was often incomplete and could only be done for the top five of most painful procedures.

For each patient, data were recorded across the entire PICU stay. The data collected at the bedside were double-checked by one investigator ( $\mathrm{SJ}$ ) for completeness in-and completed by data from-the patient data management system and the electronic patient records.

To determine the painfulness of procedures, 25 randomly chosen nurses (with number of experience years in the PICU ranging from 1 to 30 with a median of 15 ) were asked to assign a numeric rating scale (NRS) pain score (ranging from 0 to 10; 0 represents no pain and 10 represents the worst pain imaginable) to all procedures based on their general impression of painfulness, so no patient observation was involved. Procedures routinely performed under sedation or analgesia, such as thoracic drain insertion/removal, were not selected. Subsequently, we recorded the administration of procedural sedatives and analgesics during these top five procedures.

In the study PICU, endotracheal suction is performed based on a set of clinical indications, including increasing ventilation pressures, decreasing oxygen saturations, decreasing tidal volume or ventilator minute volume, increasing end-tidal $\mathrm{CO}_{2}$, visible secretions, and sawtooth pattern in the expiratory curve of the flowvolume loop.

\subsection{Statistical analysis}

Demographics are presented with descriptive statistics as medians with IQRs. Neonatal vs. non-neonatal, postsurgery vs. nonpostsurgery, and mechanically ventilated vs. non-mechanically ventilated patient group comparisons were based on the mean number of daily procedures per patient (i.e. the total number of recorded procedures per patient divided by the number of observation days) and performed with the Mann-Whitney $U$ test for non-normal distributions of variables and Student $t$ test for normally distributed variables. A Pearson correlation coefficient was performed for the linear correlation of severity-of-illness and the number of painful/stressful procedures. Data were collected per calendar day, and therefore, the patient's first observation day is not equal to the first $24 \mathrm{~h}$ of admission. SPSS (version 21; IBM Corp., 


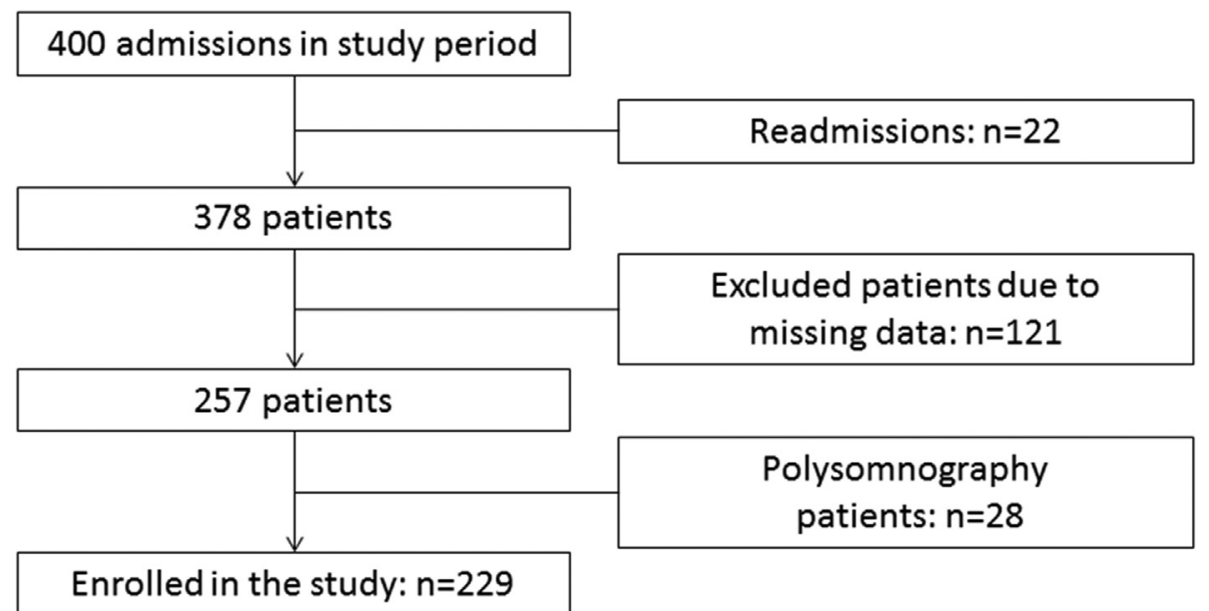

Fig. 1. Inclusion flowchart

Armonk, NY, USA) was used for all analyses. A p value $<0.05$ was considered statistically significant.

\section{Results}

Four hundred admissions occurred during the study period, one-quarter of the total number of admissions $(n=1597)$ in 2016. After exclusion of readmissions $(n=22)$, of patients of whom no record forms were available $(n=121)$ and of patients admitted for polysomnography $(\mathrm{n}=28), 229$ patients were enrolled, accounting for 855 patient days (see Fig. 1). Of the 121 excluded patients with missing record forms, 91 (75\%) had been admitted for less than $24 \mathrm{~h}$ and $28(23 \%)$ had been admitted for 24-48 h. Of all included patients, 97 (42\%) had been admitted for less than $24 \mathrm{~h}$. Patient characteristics are displayed in Table 1.

Table 1

Patient characteristics.

\begin{tabular}{ll}
\hline Characteristic & Value \\
\hline Age in months (median, IQR) & $15(3-111)$ \\
Neonate (aged $\leq 28$ days) n, (\%) & $40(17.5 \%)$ \\
Boy/girl, n (\%) & $131 / 98(57.2 / 42.8)$ \\
Length of stay in days (median, IQR) & $2(2-5)$ \\
Study observation days per patient (median, IQR) & $2(1-4)$ \\
Mechanical ventilation during data & \\
$\quad$ collection period, n (\%) & \\
Not & $166(72 \%)$ \\
Part of admission & $36(16 \%)$ \\
Whole admission & $27(12 \%)$ \\
ECMO, n (\%) & $5(2.2 \%)$ \\
PRISM-III score (median, IQR) & $3(0-6)$ \\
PIM-2 score (median, IQR) & $0.7(0.3-2.1)$ \\
Diagnosis category & $\mathbf{N}(\%)$ \\
Postoperative & \\
Yes & $116(51 \%)$ \\
No & $113(49 \%)$ \\
Cardiac & $56(25 \%)$ \\
Respiratory & $54(24 \%)$ \\
Neurological & $47(21 \%)$ \\
Gastro-intestinal & $24(11 \%)$ \\
Musculoskeletal & $14(6 \%)$ \\
Infection & $5(2 \%)$ \\
Urogenital & $4(2 \%)$ \\
Otolaryngological & $3(1 \%)$ \\
Other & $22(10 \%)$ \\
\hline Abrevians: ECMO & \\
\hline
\end{tabular}

Abbreviations: $\mathrm{ECMO}=$ extracorporeal membrane oxygenation; IQR $=$ interquartile range; PIM = paediatric index of mortality; PRISM = paediatric risk of mortality.

\subsection{Painful and stressful procedures}

In total, 14,723 procedures were recorded during 855 patient days. A median number of $11(\mathrm{IQR}=5-23)$ procedures had been recorded per patient per day, with a maximum of 113 in a patient who needed frequent endotracheal suctioning (93 times).

Further exploration of painful and stressful procedures identified that the median number of painful procedures was 7 $(\mathrm{IQR}=2-19)$ and the median number of stressful procedures was 3 $(\mathrm{IQR}=1-5)$. Endotracheal suctioning was the most frequent procedure ( $n=6697,45.5 \%$ ). Table 2 identifies the top 10 most frequent painful and stressful procedures, including the median (IQR) pain score assigned by the 25 nurses (see also Fig. 2). The daily number of procedures tended to increase with longer duration of admission (Fig. 3).

Table 2

Top 10 most frequently performed painful and stressful procedures with their perceived painfulness according to 25 nurses.

\begin{tabular}{|c|c|c|c|}
\hline & Procedure & $\begin{array}{l}\text { Total number of } \\
\text { procedures (\%) }\end{array}$ & $\begin{array}{l}\text { Median (IQR) } \\
\text { NRS pain }\end{array}$ \\
\hline & Painful procedures & & \\
\hline 1 & Endotracheal suctioning & $6697(45.5 \%)$ & $2(1-5)$ \\
\hline 2 & Oral suctioning & $1166(7.9 \%)$ & $2(2-5)$ \\
\hline 3 & Nasal suctioning & $1153(7.8 \%)$ & $3(2-5)$ \\
\hline 4 & Adhesive removal & $326(2.2 \%)$ & $3(2-4)$ \\
\hline 5 & Heel stick attempts & $282(1.9 \%)$ & $4(3-6)$ \\
\hline 6 & Finger stick attempts & $220(1.5 \%)$ & $4(3-6)$ \\
\hline 7 & $\begin{array}{l}\text { Nasal flow cannula or } \\
\text { nasal prongs placement }\end{array}$ & $176(1.2 \%)$ & $1(0-1)$ \\
\hline 8 & $\begin{array}{l}\text { Peripheral IV cannula } \\
\text { insertion attempts }\end{array}$ & $170(1.2 \%)$ & $6(4-8)$ \\
\hline 9 & $\begin{array}{l}\text { Peripheral IV cannula } \\
\text { removal }\end{array}$ & $137(0.9 \%)$ & $1(1-2)$ \\
\hline 10 & $\begin{array}{l}\text { Wound dressing } \\
\text { Stressful procedures }\end{array}$ & $119(0.8 \%)$ & $4(4-6)$ \\
\hline 1 & Spraying & $1074(7.3 \%)$ & $0(0-1)$ \\
\hline 2 & ADL care & $930(6.3 \%)$ & Not asked \\
\hline 3 & EMV score & $421(2.9 \%)$ & Not asked \\
\hline 4 & X-ray & $202(1.4 \%)$ & Not asked \\
\hline 5 & General ultrasonography & $127(0.9 \%)$ & Not asked \\
\hline 6 & Weighing & $103(0.7 \%)$ & Not asked \\
\hline 7 & Electrocardiography & $82(0.6 \%)$ & Not asked \\
\hline 8 & Physiotherapy & $69(0.5 \%)$ & Not asked \\
\hline 9 & Cranial ultrasonography & $33(0.2 \%)$ & Not asked \\
\hline 10 & Electroencephalography & $26(0.2 \%)$ & $1(0-3)$ \\
\hline
\end{tabular}

Abbreviations: $\mathrm{ADL}=$ activities of daily living; $\mathrm{EMV}=$ eye opening, motor response, verbal response score; IQR = interquartile range; IV = intravenous.

All failed attempts and the final successful ones are counted as separate procedures. 


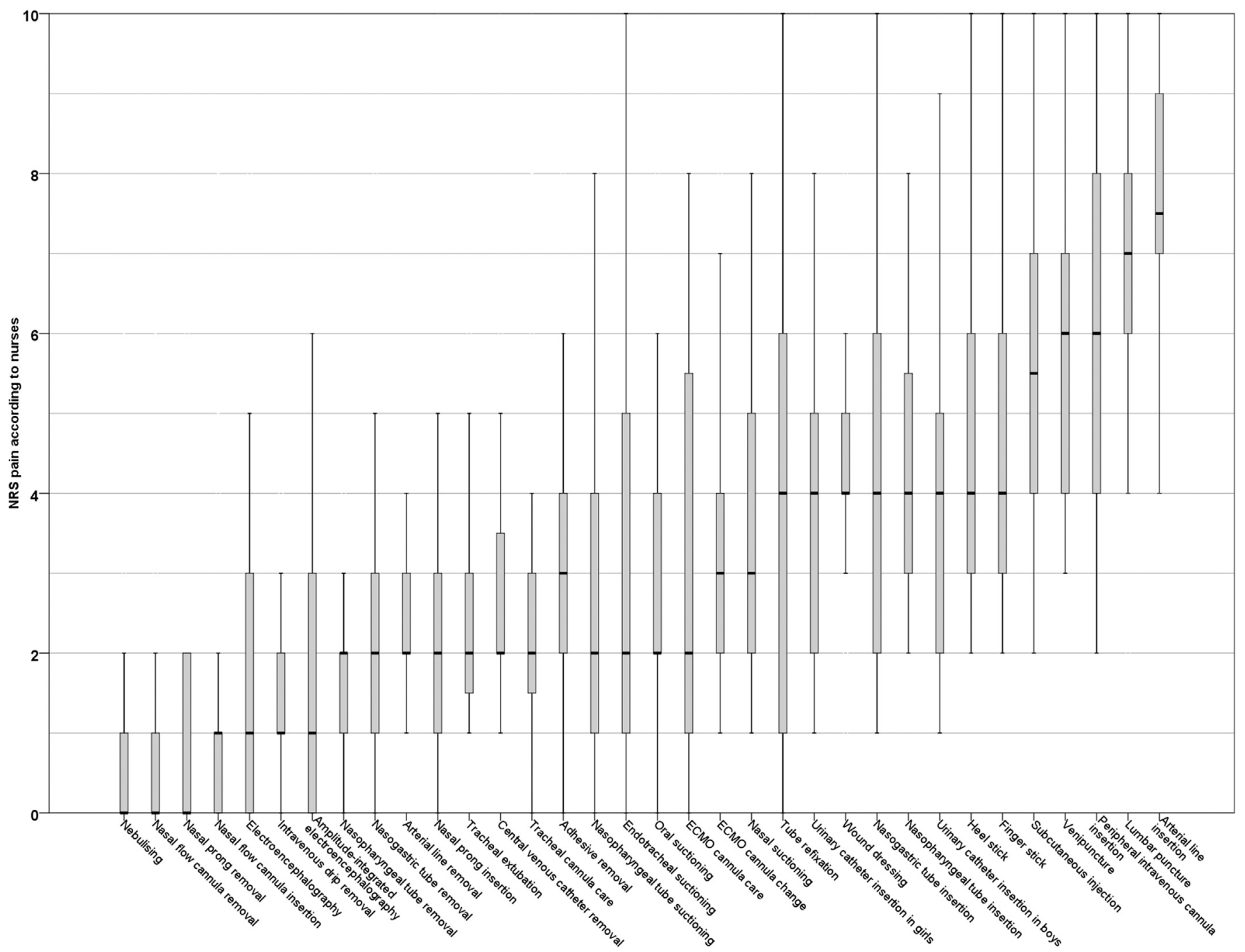

Fig. 2. Box plot of ratings by 25 paediatric intensive care nurses of the painfulness of the listed procedures in ascending order.

The number of painful and stressful daily procedures in the group of neonates (median $=9, \mathrm{IQR}=7-17$ ) was significantly higher than in the group of children $>28$ days (median $=7$, $\mathrm{IQR}=4-14)(\mathrm{p}=0.05)$. Regarding a comparison between mechanically ventilated and non-mechanically ventilated patients, the total number of procedures was significantly higher in the former group: median $=15(\mathrm{IQR}=9-22)$ versus median $=6$ per day $(\mathrm{IQR}=3-10),(\mathrm{p}<0.001)$. Non-ventilated patients received significantly less painful procedures than ventilated patients: median $=2$ $(\mathrm{IQR}=1-6)$ versus median $=10(\mathrm{IQR}=5-19)$. They also received fewer stressful procedures: $2(\mathrm{IQR}=1-5)$ versus $3(\mathrm{IQR}=2-5)$.

Postoperative patients underwent significantly fewer procedures per day (median $=7, \mathrm{IQR}=4-12$ versus median $=9$, $\mathrm{IQR}=4-17, \mathrm{p}=0.03$ ), with no significant difference in the number of painful procedures but a significantly lower number of stressful procedures: median $=2(\mathrm{IQR}=1-4)$ versus median $=3$ $(\mathrm{IQR}=1-5)$.

There was a low correlation between severity of illness and the mean number of procedures per patient per day. Correlation for the PRISM-III score was 0.26 (95\% confidence interval $=0.13-0.38$ ) and for the PIM-2 score 0.20 (95\% confidence interval $=0.07-0.32$ ).

Table 3 shows the total numbers of attempt per intended procedure. We observed a lower success rate (i.e. procedures without multiple attempts) for lumbar puncture, arterial line insertion, peripheral IV cannula insertion, and venipuncture (Table 4).

\subsection{Procedural analgesia and sedation}

Background analgosedation during procedures is illustrated by Fig. 4a (for the procedures rated most painful) and Fig. 4b (for the most frequent procedures). Continuous opioid administration was used in less than $40 \%$ of these procedures. For a full overview of background analgosedation during all procedures see Appendix 3. Table 5 shows the procedural analgesic and sedative treatment of the top five most painful procedures: arterial line insertion, lumbar puncture, peripheral IV cannula insertion, venipuncture, and subcutaneous injection. Although in the top five, venipuncture and subcutaneous injection have not been treated with procedural systemic analgesics or sedatives at all. Arterial line insertion was also covered in $25 \%$ of procedures. Two out of three lumbar punctures were covered by procedural analgosedation. Ketamine was the most frequently used agent, often accompanied by midazolam or propofol.

One patient underwent endotracheal suctioning 93 times in a day. This patient was admitted for a viral airway infection and received continuous midazolam and morphine. 


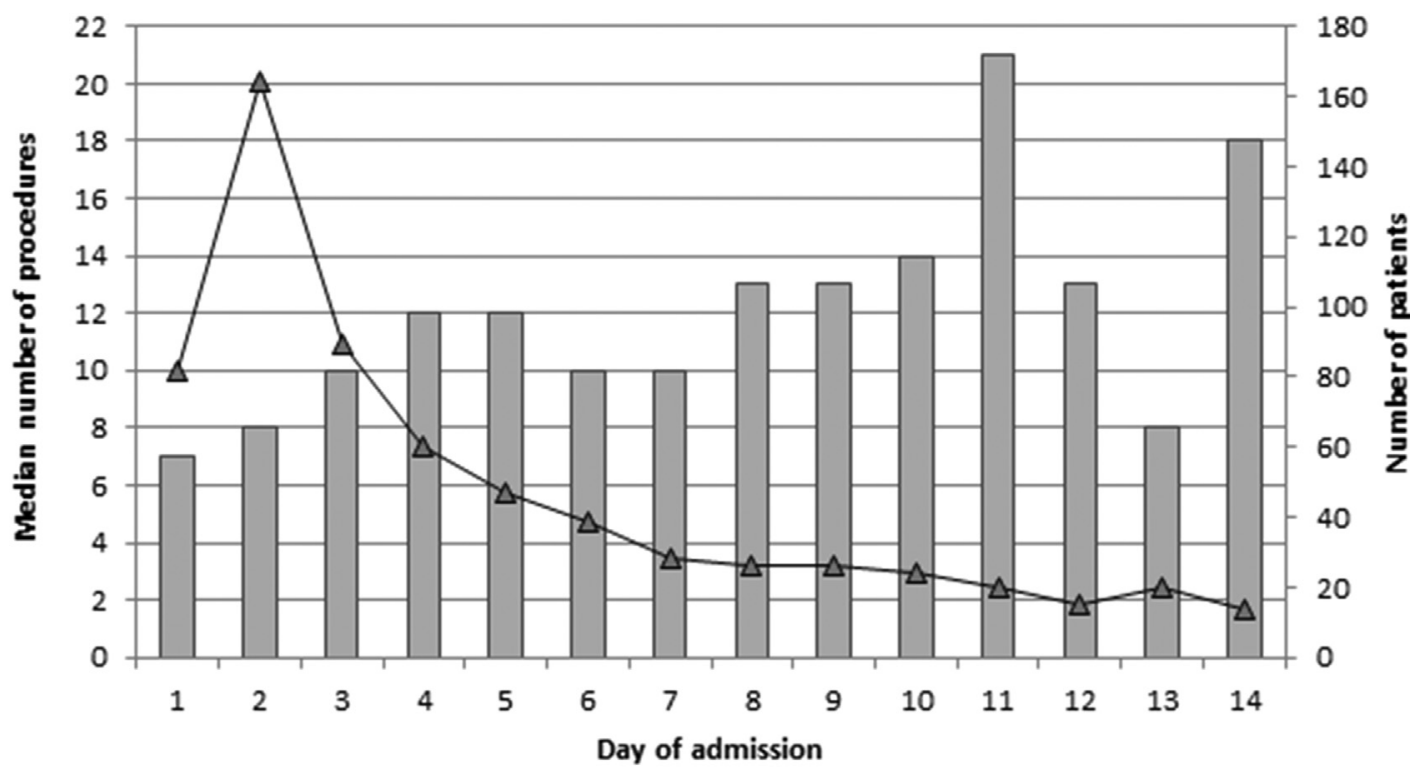

$\square$ Median number procedures $\quad \triangle$ Number of patients

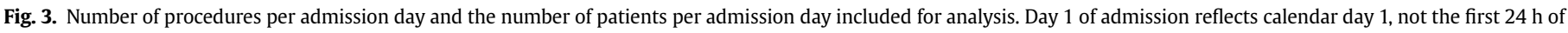
admission.

Table 3

Numbers of attempt and success rate per painful procedure.

\begin{tabular}{llll}
\hline Procedures & $\begin{array}{l}\text { Number of } \\
\text { intended } \\
\text { procedures }\end{array}$ & $\begin{array}{l}\text { Total number } \\
\text { including failed } \\
\text { attempts }\end{array}$ & $\begin{array}{l}\text { Percentage of } \\
\text { procedures with } \\
\text { success in one } \\
\text { attempt }\end{array}$ \\
\hline Subcutaneous injection & 34 & 34 & $100 \%$ \\
Thoracic drain insertion & 5 & 5 & $100 \%$ \\
Urinary catheter insertion & 25 & 26 & $95.8 \%$ \\
Nasogastric tube insertion & 90 & 93 & $95.7 \%$ \\
Finger stick for blood sampling & 192 & 220 & $90.2 \%$ \\
Heel stick for blood sampling & 256 & 282 & $89.9 \%$ \\
Central venous catheter & 23 & 36 & $86.4 \%$ \\
$\quad$ insertion & 9 & 11 & $77.8 \%$ \\
Endotracheal intubation & 9 & 170 & $68.8 \%$ \\
Peripheral IV cannula insertion & 88 & 7 & $66.7 \%$ \\
Lumbar puncture & 3 & 45 & $65.0 \%$ \\
Arterial line insertion & 23 & 50 & $57.9 \%$ \\
Venipuncture for blood & 28 & & \\
$\quad$ sampling & & & \\
\hline
\end{tabular}

IV = intravenous

\section{Discussion}

This first prospective observational cohort study on the frequency of painful and stressful procedures in the PICU setting

Table 4

Number of painful and stressful procedures covered by an analgesic or a sedative.

\begin{tabular}{lll}
\hline & Painful procedures & Stressful procedures \\
\hline Paracetamol & $1950(17.1 \%)$ & $791(23.7 \%)$ \\
Paracetamol + NSAID & $119(1.0 \%)$ & $102(3.1 \%)$ \\
Any opioid & $321(2.8 \%)$ & $111(3.3 \%)$ \\
Sedative alone & $988(8.7 \%)$ & $189(5.6 \%)$ \\
Sedative + PCM & $1128(9.9 \%)$ & $211(6.3 \%)$ \\
Sedative + opioid & $4378(38.5)$ & $888(26.6 \%)$ \\
No analgesic or sedative & $2502(22 \%)$ & $1045(31.3 \%)$ \\
\hline
\end{tabular}

NSAID = non-steroidal anti-inflammatory drugs; $\mathrm{PCM}=$ paracetamol. revealed a median number of 11 per patient per day. Endotracheal suctioning was most frequent, followed by oral and nasal suctioning. Nurses ranked lumbar puncture, arterial puncture, peripheral IV cannula insertion, and venipuncture as the most painful procedures, and for those, often more than one attempt was needed to be successful.

The findings of this study are comparable to findings from previous studies in the NICU setting, ${ }^{5-7,9}$ although the total population differs. The current study includes neonates, and this group formed $17.5 \%$ of the total population. The median number of procedures $(9, \mathrm{IQR}=7-17)$ in this group was lower than that in the NICU studies. Possible explanations are the inclusion of more premature neonates in the NICU studies compared to the study PICU where neonates are admitted after surgery only. Additionally, the neonates in this study had already undergone many procedures before admission at the PICU, for example endotracheal intubation and the insertion of arterial lines, central venous lines, peripheral IV cannulas, bladder catheters, and nasogastric tubes as part of the perioperative procedures in the operating room. The number of procedures also varied between studies. The current study included a total of 40 procedures compared to the study by Carbajal et $\mathrm{al}^{5}$ which included 24, and the studies by Simons et $\mathrm{al}^{7}$ and Roofthooft et $\mathrm{al}^{6}$ included 34 procedures. The current study overlapped with the total of these two studies, but extracorporeal membrane oxygenation and tracheal cannula care, nebulising, computed tomography and magnetic resonance imaging scans, and urinary catheter insertion were not listed. The inclusion of these additional procedures in the NICU studies could have increased their number of painful and stressful procedures.

With regard to the PICU, a multi-centre study in 15 Canadian PICUs from 2007 to 2008 recorded a median of 12 painful procedures per day. ${ }^{3}$ In our present study, 9 years later, we found a median of seven painful procedures per day. This lower number could be explained by the fact that this study did not include procedures performed before admission to the PICU, such as endotracheal intubation, line insertion, and needle sticks in the emergency department, operating room, or referring hospitals. 
Table 5

Procedural analgesic and sedative bolus administration for treatment of pain during the five most painful procedures.

\begin{tabular}{lll}
\hline Procedure & $\begin{array}{l}\text { Covered by procedural } \\
\text { analgosedative }(\mathrm{n}, \%)\end{array}$ & Drugs used \\
\hline $\begin{array}{l}\text { Top } 5 \text { most painful procedures } \\
\begin{array}{l}\text { 1. Arterial line } \\
\text { insertion }(\mathrm{n}=20)\end{array}\end{array}$ & $5(25 \%)$ & $\begin{array}{l}\text { Ketamine }(\mathrm{n}=3) \\
\text { Propofol }(\mathrm{n}=3)\end{array}$ \\
& & $\begin{array}{l}\text { Fentanyl }(\mathrm{n}=2) \\
\text { Midazolam }(\mathrm{n}=1)\end{array}$ \\
$\begin{array}{l}\text { 2. Lumbar puncture } \\
(\mathrm{n}=3)\end{array}$ & $2(67 \%)$ & $\begin{array}{l}\text { Ketamine }(\mathrm{n}=2) \\
\text { Propofol }(\mathrm{n}=1)\end{array}$ \\
$\begin{array}{l}\text { 3. Peripheral IV cannula } \\
\text { insertion }(\mathrm{n}=77)\end{array}$ & $5(6.5 \%)$ & $\begin{array}{l}\text { Midazolam }(\mathrm{n}=1) \\
\text { Midazolam }(\mathrm{n}=3)\end{array}$ \\
$\begin{array}{l}\text { 4. Venipuncture }(\mathrm{n}=28) \\
\text { 5. SC injection }(\mathrm{n}=27)\end{array}$ & $0(0 \%)$ & $\begin{array}{l}\text { Ketamine }(\mathrm{n}=1) \\
\text { Propofol }(\mathrm{n}=1)\end{array}$ \\
\hline
\end{tabular}

IV = intravenous; SC = subcutaneous.

Whether Stevens et al. included these procedures is not clear. In addition, healthcare professionals may have become more aware of the amount of consistent procedural pain and tried to minimise the number of painful procedures, for example by changing routine endotracheal suctioning to criteria-led suctioning.

Not surprisingly, the number of daily procedures is highest in the mechanically ventilated patients, as suctioning involves almost half of all procedures. In the NICU studies, nasal and endotracheal suctioning are also the most frequent procedures. ${ }^{6,7}$ In the current study, low numbers of both procedural and background analgosedation were observed for the most painful procedures, despite a well-balanced and published analgosedation regimen in place. ${ }^{11,12}$ Background analgosedation was used more often during the most frequent procedures; this could be attributed to the fact that suctioning is performed more often in mechanically ventilated patients who are usually sedated.

\subsection{Limitations}

One of the limitations of this study is the risk of bias by underreporting. For lack of time or attention, nurses may not have recorded all procedures on the checklist during a shift or considered some procedures not painful or stressful as they could have not had enough time to review the case report form. Also, selection bias could have occurred due to the missing data from short admissions, although the majority of these patients were admitted for polysomnography and otherwise excluded from the study. The researchers double-checked reporting against the medical records, which nevertheless might also be incomplete. Also, the most painful procedures were selected based on survey results among 25 randomly selected nurses (accounting for 15\% of total PICU nursing staff). This is a method prone to a certain degree of subjectivity. Still, in another observational study, skin-breaking procedures were ranked most painful as in the current study. ${ }^{15}$ Moreover, painfulness and stressfulness cannot always be easily distinguished. For example, the most frequent procedure, endotracheal suctioning, has been regarded as painful in the literature ${ }^{16,17}$ but may be stressful as well. ${ }^{18-20}$ Our survey shows a high variability in responses by nurses to endotracheal suctioning. The observed pain behaviour during endotracheal suctioning in studies using several pain scales could also be a response to stress, as this is a very frightening, unpleasant procedure.

\subsection{Interpretation}

The painfulness of a procedure can vary within and between patients, although this needs further study. For example, activities of daily living may normally not be painful but may be very painful in a patient after severe trauma. Perceptions of painfulness may also affect pain management. For example, in our hospital, topical anaesthesia is frequently used before peripheral IV cannula insertion but is rarely ever used before heel or finger sticks. This is remarkable as these procedures may not differ in painfulness. Further study is warranted to explore the perception of painfulness of procedures and standardisation of procedural pain management by performing prospective evaluation of pain during procedures.

\subsection{Future perspectives}

Painful and stressful procedures are, unfortunately, unavoidable in paediatric critical care. Measures to reduce the number of these procedures should be considered. To reduce the frequency of endotracheal suctioning, which was found most frequent, we could recommend re-considering the indications for endotracheal suctioning. In the study centre, suctioning is performed only at indications supported by current evidence. Prospective evaluation of
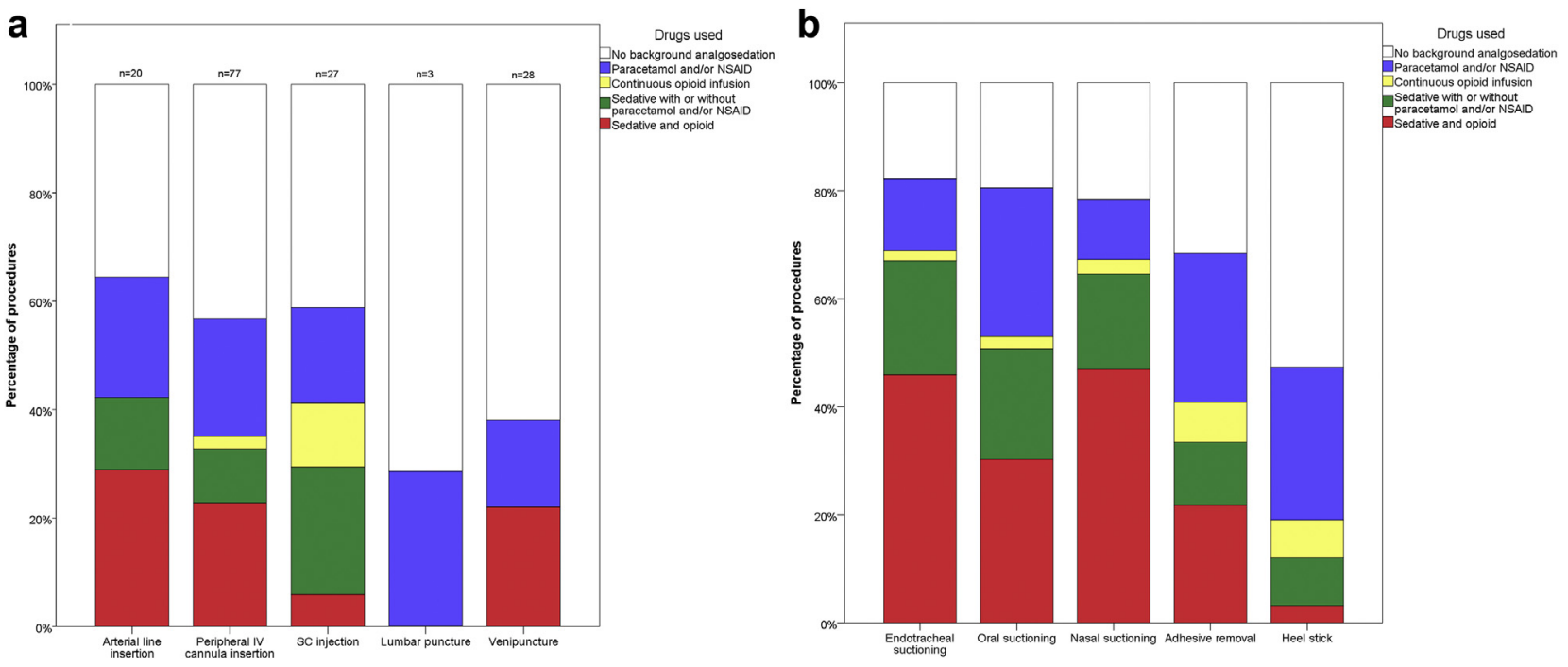

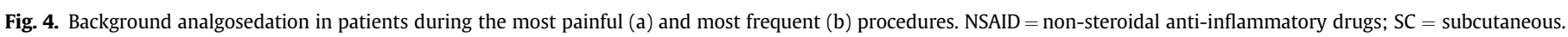


these indications in relation to the need of suction could possibly reduce the frequency of suctioning by identifying the strongest indications and by performing suctioning only for the strong indications. $^{21}$

Another way of reducing the frequency of painful procedures is to improve technical skills to reduce the number of attempts for certain procedures that required multiple attempts. These were also ranked as most painful procedures: lumbar puncture, peripheral cannula insertion, arterial puncture, and venipuncture. The number of lumbar puncture attempts may be improved through the use of simulation training ${ }^{22}$ or with the use of ultrasound. ${ }^{23,24}$ Ways of improving venipuncture and peripheral IV cannula insertion are yet to be established because so far vein visualisation techniques have not been proven to be effective in reducing the number of failed attempts of IV cannula insertion or venipuncture. ${ }^{25-27}$

Standardisation of pain-reducing measures, both pharmacologic and non-pharmacologic, could improve the quality of care for critically ill children. NICU guidelines recommend several measures such as oral sucrose administration, facilitated tucking position, and non-nutritive sucking. ${ }^{28}$ However, guidelines for the PICU are not available yet. In the study centre, oral sucrose is administered to neonates; however, this is not a standardised practice. Eutectic mixture of local anaesthetic is also available but is only used in older children and is also not standardised. Uniform guidelines should be established to improve the analgesic management of painful procedures.

\section{Conclusions}

The PICU patients in this study on average underwent seven painful and three stressful procedures per day. Mechanically ventilated patients undergo more than twice as many painful procedures than non-ventilated patients, as endotracheal suctioning accounts for almost half of all. Nurses regarded skin-breaking procedures most painful but these procedures were rarely covered by procedural analgosedation and only in less than half of the cases continuous background analgosedation was used. Measures to reduce the number of painful procedures could include revision of indications for endotracheal suctioning and improving technical skills through training and/or the use of assistant devices such as ultrasound guidance.

\section{Funding}

This research did not receive any specific grant from funding agencies in the public, commercial, or not-for-profit sectors.

\section{Author contributions}

MB was involved in the study design, data collection and writing the manuscript. SJ was involved in the study design and data collection. EI, KA, and DT were involved in parts of the study design and contributed to the manuscript. MvD was involved in the study design, data collection, and writing the manuscript.

\section{Acknowledgements}

The authors thank all ICU nurses for their effort to record all painful and stressful procedures and Ko Hagoort for editorial assistance.

\section{Appendix A. Supplementary data}

Supplementary data related to this article can be found at https://doi.org/10.1016/j.aucc.2018.04.003.

\section{References}

[1] Playfor S, Jenkins I, Boyles C, Choonara I, Davies G, Haywood T, et al. Consensus guidelines on sedation and analgesia in critically ill children. Intensive Care Med 2006;32:1125-36.

[2] Harris J, Ramelet AS, van Dijk M, Pokorna P, Wielenga J, Tume L, et al. Clinical recommendations for pain, sedation, withdrawal and delirium assessment in critically ill infants and children: an ESPNIC position statement for healthcare professionals. Intensive Care Med 2016;42:972-86.

[3] Stevens BJ, Abbott LK, Yamada J, Harrison D, Stinson J, Taddio A, et al, Epidemiology and management of painful procedures in children in Canadian hospitals. CMAJ 2011;183:E403-10.

[4] Carbajal R, Eriksson M, Courtois E, Boyle E, Avila-Alvarez A, Andersen RD, et al. Sedation and analgesia practices in neonatal intensive care units (EUROPAIN): results from a prospective cohort study. Lancet Respir Med 2015;3:796-812.

[5] Carbajal R, Rousset A, Danan C, Coquery S, Nolent P, Ducrocq S, et al. Epidemiology and treatment of painful procedures in neonates in intensive care units. JAMA 2008;300:60-70.

[6] Roofthooft DW, Simons SH, Anand KJ, Tibboel D, van Dijk M. Eight years later, are we still hurting newborn infants? Neonatology 2014;105:218-26.

[7] Simons SH, van Dijk M, Anand KS, Roofthooft D, van Lingen RA, Tibboel D. Do we still hurt newborn babies? A prospective study of procedural pain and analgesia in neonates. Arch Pediatr Adolesc Med 2003;157:1058-64.

[8] Barker DP, Rutter N. Exposure to invasive procedures in neonatal intensive care unit admissions. Arch Dis Child Fetal Neonatal Ed 1995;72:F47-8.

[9] Cruz MD, Fernandes AM, Oliveira CR. Epidemiology of painful procedures performed in neonates: a systematic review of observational studies. Eur J Pain 2016;20:489-98.

[10] Southall DP, Cronin BC, Hartmann H, Harrison-Sewell C, Samuels MP. Invasive procedures in children receiving intensive care. BMJ 1993;306:1512-3.

[11] Ista E, de Hoog M, Tibboel D, van Dijk M. Implementation of standard sedation management in paediatric intensive care: effective and feasible? J Clin Nurs 2009;18:2511-20.

[12] Vet NJ, de Wildt SN, Verlaat CW, Knibbe CA, Mooij MG, van Woensel JB, et al. A randomized controlled trial of daily sedation interruption in critically ill children. Intensive Care Med 2016;42:233-44.

[13] Slater A, Shann F, Pearson G. Paediatric index of mortality study G. PIM2: a revised version of the paediatric index of mortality. Intensive Care Med 2003;29:278-85.

[14] Pollack MM, Patel KM, Ruttimann UE. PRISM III: an updated pediatric risk of mortality score. Crit Care Med 1996;24:743-52.

[15] Akgün D, Inal S. Determination of pain generating levels of nursing activities in pediatric intensive care patients. 2017. ESPNIC Meeting. Lisbon.

[16] Sonmez Duzkaya D, Kuguoglu S. Assessment of pain during endotracheal suction in the pediatric intensive care unit. Pain Manag Nurs 2015;16:11-9.

[17] Arroyo-Novoa CM, Figueroa-Ramos MI, Puntillo KA, Stanik-Hutt J, Thompson CL, White C, et al. Pain related to tracheal suctioning in awake acutely and critically ill adults: a descriptive study. Intensive Crit Care Nurs $2008 ; 24: 20-7$

[18] Simons SH, van Dijk M, van Lingen RA, Roofthooft D, Duivenvoorden HJ, Jongeneel $\mathrm{N}$, et al. Routine morphine infusion in preterm newborns who received ventilatory support: a randomized controlled trial. JAMA 2003;290: 2419-27.

[19] Valitalo PA, van Dijk M, Krekels EH, Gibbins S, Simons SH, Tibboel D, et al. Pain and distress caused by endotracheal suctioning in neonates is better quantified by behavioural than physiological items: a comparison based on item response theory modelling. Pain 2016;157:1611-7.

[20] Granja C, Lopes A, Moreira S, Dias C, Costa-Pereira A, Carneiro A, et al. Patients' recollections of experiences in the intensive care unit may affect their quality of life. Crit Care 2005;9:R96-109.

[21] Morrow BM, Argent AC. A comprehensive review of pediatric endotracheal suctioning: Effects, indications, and clinical practice. Pediatr Crit Care Med 2008;9:465-77.

[22] Kessler DO, Auerbach M, Pusic M, Tunik MG, Foltin JC. A randomized trial of simulation-based deliberate practice for infant lumbar puncture skills. Simul Healthc 2011;6:197-203.

[23] Ozdamar E, Ozkaya AK, Guler E, Cantay B, Karabel N, Goksugur Y, et al. Ultrasound-assisted lumbar puncture in pediatric emergency department. Pediatr Emerg Care 2015 Aug;33(8):e21-3.

[24] Dalrymple RA. Bedside ultrasound improves the success rate of lumbar puncture in infants. Arch Dis Child Ed Pract 2017. Online first: 27 July 2017.

[25] Cuper NJ, de Graaff JC, Verdaasdonk RM, Kalkman CJ. Near-infrared imaging in intravenous cannulation in children: a cluster randomized clinical trial. Pediatrics 2013:131:e191-7.

[26] Kaddoum RN, Anghelescu DL, Parish ME, Wright BB, Trujillo L, Wu J, et al. A randomized controlled trial comparing the AccuVein AV300 device to standard insertion technique for intravenous cannulation of anesthetized children. Paediatr Anaesth 2012;22:884-9.

[27] Perry AM, Caviness AC, Hsu DC. Efficacy of a near-infrared light device in pediatric intravenous cannulation: a randomized controlled trial. Pediatr Emerg Care 2011;27:5-10.

[28] Committee on Fetus and Newborn and Section On Anesthesiology and Pain Medicine. Prevention and management of procedural pain in the neonate: an Update. Pediatrics 2016;137:1-13. 